Research Article

\title{
Assessment of knowledge, attitude and practice of dengue in factory workers of Amritsar, Punjab
}

\author{
Deepika Tikoo*, Geeta Sharma, Meenakshi Gupta
}

Department of Pharmacology, Sri Guru Ram Das Institute of Medical Sciences \&Research, Vallah, Amritsar, Punjab, India

Received: 02 January 2016

Revised: 08 January 2016

Accepted: 18 January 2016

*Correspondence to:

Dr. Deepika Tikoo,

Email: dtikoo@gmail.com

Copyright: (C) the author(s), publisher and licensee Medip Academy. This is an openaccess article distributed under the terms of the Creative Commons Attribution NonCommercial License, which permits unrestricted noncommercial use, distribution, and reproduction in any medium, provided the original work is properly cited.

\begin{abstract}
Background: Dengue, a mosquito borne, arboviral disease has become a major cause of health concern in the recent times throughout the world. In India, we have been witnessing annual outbreaks for the past few years and lack of knowledge about prevention and treatment of dengue among majority of the population leads to increased mortality. Apart from Delhi, many cases of dengue have been reported from Punjab. In spite of this fact, very few studies have been done to know about the knowledge of people regarding dengue fever and whether proper preventive measures are being practiced by the community to limit its spread. The objective of the study is to assess the knowledge, attitude \& practices (KAP) regarding dengue in factory workers in Amritsar, Punjab.

Methods: The present study was conducted among 162 factory workers of old focal point area of Amritsar in the month of November, 2015. Pre validated, self-structured questionnaires were distributed among the workers after explaining them about the purpose of the study. The questionnaire was also typed in the vernacular language (Punjabi) for the ease of the participants. A written informed consent was obtained from them. The data collected was compiled and analyzed in a pre-structured format.

Results: Among 162 workers enrolled for the study, 98.6\% were literate and majority (99.4\%) had heard about dengue fever. Almost everyone (98.8\%) was aware that it is caused by the bite of a mosquito. The major sources of information were television $(54.9 \%)$ and newspaper $(30.9 \%)$. High fever was the most common sign and symptom (49.4\%) mentioned by the workers. Only $30.9 \%$ respondents knew that aspirin should be avoided in a dengue patient. Many workers $(94.4 \%)$ were aware that standing water can be a common breeding place for the mosquitoes but still, regular cleaning of coolers or water containers was not practiced by all.

Conclusions: The present study shows that literacy status of an individual is not associated with adequate knowledge and its application. The study population had insufficient information about dengue while the preventive measures which were known to them for limiting the spread of dengue was not satisfactorily practiced. We as health care professionals should undertake more of these studies to know about the knowledge status of the community and hold health awareness camps. The government should also adopt frequent measures to spread such information through television, newspapers, posters and campaigns.
\end{abstract}

Keywords: Knowledge, Attitude, Practice, Dengue, Factory workers

\section{INTRODUCTION}

Dengue fever is a mosquito borne viral disease which is rapidly spreading around the world and becoming a major global health concern. ${ }^{1}$ In India, annual outbreaks are reported every year with peak incidence in the months of
September to November. ${ }^{2}$ In the year 2014, more than ten thousand cases of dengue were reported from India and the incidence was almost double in the year $2015 .^{3}$ In the absence of any definitive therapy or vaccine to control dengue, vector control programmes to control Aedes aegypti and Aedes albopictus and limit their spread to 
newer areas is the best possible way to combat this issue. ${ }^{4}$ Therefore active community participation by organizing frequent health education programmes which aims at improving the knowledge about dengue, attitude towards the disease and preventive practice to limit its spread is the need of the hour. It is also important to have a sound knowledge about the correct treatment practice undertaken for dengue to prevent its complications. In the present study, we tried to determine the knowledge, attitude and practice regarding dengue among factory workers in Amritsar via a pre validated questionnaire, as there is paucity of such studies in this area.

\section{METHODS}

The present study was conducted among 162 factory workers in old focal point area of Amritsar by distributing a pre validated, self-structured questionnaire. The questionnaire was also typed in the vernacular language (Punjabi) for the ease of the participants. The workers were first explained about the purpose of the study and a written informed consent was then obtained from them. The data collected was compiled and analyzed in a pre-structured format.

\section{RESULTS}

A total of 200 factory workers were approached for the study and 162 among them gave their consent for participation in the study. The workers were all male. The data from these 162 respondents was successfully obtained and analyzed. Among the factory workers, $46.3 \%$ were in the age group of $18-25$ years, $32.7 \%$ were between $26-35$ years of age, $15.4 \%$ were in the age group of 36-45 years and 5.5\% were within 46-65 years of age. Majority of the respondents $(98.6 \%)$ were literates.

\section{Knowledge about dengue fever}

Majority of the workers (99.4\%) had heard about dengue fever and mostly $(98.8 \%)$ were aware that it is caused by the bite of a mosquito. The major sources of information were television (54.9\%), newspaper (30.9\%), friends/relatives (16\%) etc. (Figure 1). About $4.9 \%$ felt that dengue can be caused by the consumption of dirty food and drinking water. The results are summarized in Table 1.The knowledge about the day biting behaviour of the mosquito was seen in $45.7 \%$ workers while $38.9 \%$ felt that the mosquito can bite both during day or night time while $14.2 \%$ answered that it bites during night time. About $64.2 \%$ workers responded that dengue peaks in the rainy season (July-August), $18.4 \%$ said that the peak months for dengue are autumn months (SeptemberNovember) while $11.1 \%$ felt that dengue is most prevalent in summers (April-June) and 2.5\% workers even thought of winters (December-February) as peak months for dengue fever. About $43.8 \%$ workers knew that dengue could be transmitted by blood transfusion. Others mentioned that needle stick injury, sharing of food $\&$ clothes with the patient can spread dengue. It was good to know that many workers $(94.4 \%)$ were aware that standing water can be a common breeding place for the mosquitoes while few also said the garbage collection and burrows/pits can also harbour mosquitoes. When asked about the signs and symptoms of dengue, high fever was the most common response (49.4\%). Around $38.3 \%$ had the knowledge that a patient of dengue could present with any of the signs and symptoms like fever, body-aches, nausea \& vomiting, red spots on the body, diarrhoea or pain abdomen. Very few (1.2\%) were not aware of any of the presentations of dengue fever. We wanted to know that are the rural people aware that the testing for dengue is available in most of the city laboratories and $63.6 \%$ workers had the information. When asked about the knowledge about treatment and complications of dengue, only $30.9 \%$ respondents knew that aspirin should never be given to a patient of dengue, $41.3 \%$ did not know what medicines should be avoided in a patient of dengue while $11.1 \%$ also replied that paracetamol cannot be given to a patient of dengue. It was seen that $96.9 \%$ of workers had the knowledge that dengue is treatable. They answered that as soon as dengue is suspected, immediate medical help should be sought; many workers $(91.3 \%)$ knew that consumption of kiwi fruit is beneficial in a patient of dengue while few (7.4\%) thought of papaya as a beneficial therapy. Others mentioned that keeping the surroundings clean, wearing full sleeved clothes, consumption of goat's milk, eating paracetamol with plenty of liquid diet, avoiding antibiotics are also the treatment measures for dengue. Low platelet count as a complication of dengue was the most common response $(54.9 \%)$, followed by dengue haemorrhagic fever (14.2\%).

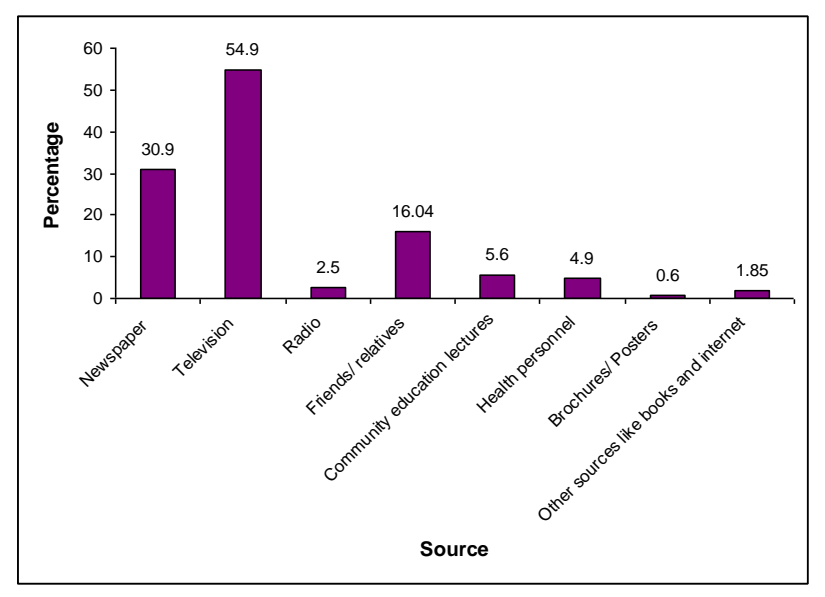

Figure 1: Sources of information about dengue fever.

\section{Attitude towards dengue fever}

On assessment of the attitude of the workers regarding dengue, it was seen that $35.2 \%$ thought that they might be at risk of getting dengue while $27.8 \%$ absolutely agreed about being at risk of suffering from dengue. Some $(27.2 \%)$ said that they take all the necessary precautions against dengue and $9.8 \%$ did not know if they are at risk. 
Majority of the respondents $(91.4 \%)$ have never tried to treat any family member or friend suffering from dengue on their own. Few $(2.5 \%)$ said that they tried to give home remedies like juice of papaya rind, plenty of fluids, goat's milk to a dengue patient.

Table 1: Knowledge about dengue fever.

\begin{tabular}{|c|c|c|}
\hline Questions & Number & Percentage $(\%)$ \\
\hline \multicolumn{3}{|l|}{ Have you ever heard about dengue? } \\
\hline No & Nil & Nil \\
\hline Yes & 161 & 99.4 \\
\hline May be & 1 & 0.6 \\
\hline \multicolumn{3}{|l|}{ What is the cause of dengue? } \\
\hline Bite of mosquito & 160 & 98.8 \\
\hline Bite of housefly & Nil & Nil \\
\hline Consumption of dirty food/ drinking water & 8 & 4.9 \\
\hline Don’t know & Nil & Nil \\
\hline \multicolumn{3}{|c|}{ At what time does the dengue causing mosquito most likely bite? } \\
\hline Night time & 23 & 14.2 \\
\hline Day time & 74 & 45.7 \\
\hline Both night and day time & 63 & 38.9 \\
\hline Don’t know & 1 & 0.6 \\
\hline No response & 1 & 0.6 \\
\hline \multicolumn{3}{|l|}{ During which part of the year is dengue most prevalent? } \\
\hline Summers (April-June) & 18 & 11.1 \\
\hline Rainy season (July-August) & 104 & 64.2 \\
\hline Autumn (September- November) & 30 & 18.5 \\
\hline Winters (December- February) & 4 & 2.5 \\
\hline No response & 6 & 3.7 \\
\hline \multicolumn{3}{|l|}{ Dengue can be transmitted by : } \\
\hline Human to human contact & 6 & 3.7 \\
\hline Blood transfusion & 71 & 43.8 \\
\hline Needle stick injury & 21 & 12.96 \\
\hline Sharing of food/ clothes with the patient & 10 & 6.2 \\
\hline None of the above & 36 & 22.2 \\
\hline Don’t know & 14 & 8.6 \\
\hline No response & 4 & 2.5 \\
\hline \multicolumn{3}{|l|}{ What is the common breeding place for mosquitoes? } \\
\hline Burrows and pits & 5 & 3.1 \\
\hline Standing water (coolers, utensils, bucket, flower pots etc) & 153 & 94.4 \\
\hline Plants & 1 & 0.6 \\
\hline Garbage & 11 & 6.8 \\
\hline Don’t know & Nil & Nil \\
\hline \multicolumn{3}{|l|}{ What are the signs and symptoms of dengue? } \\
\hline High fever & 80 & 49.4 \\
\hline Severe body aches & 4 & 2.5 \\
\hline Nausea and vomiting & 7 & 4.3 \\
\hline Red spots on the body & 16 & 9.8 \\
\hline Diarrhoea & 2 & 1.2 \\
\hline Pain abdomen & 1 & 0.6 \\
\hline All of the above & 62 & 38.3 \\
\hline Don’t know & 2 & 1.2 \\
\hline \multicolumn{3}{|c|}{ Is the facility of testing for dengue available at each and every laboratory? } \\
\hline Yes & 103 & 63.6 \\
\hline No & 44 & 27.2 \\
\hline Don’t know & 15 & 9.2 \\
\hline \multicolumn{3}{|l|}{ Are you aware of any ayurvedic/ herbal remedy for dengue? } \\
\hline Yes & 24 & 14.8 \\
\hline No & 125 & 77.2 \\
\hline No response & 13 & 8.0 \\
\hline
\end{tabular}




\begin{tabular}{|c|c|c|}
\hline \multicolumn{3}{|c|}{$\begin{array}{l}\text { Do you know that which medication(s) should NEVER be given to a patient } \\
\text { suffering from dengue? }\end{array}$} \\
\hline Aspirin & 50 & 30.9 \\
\hline Ibuprofen & 13 & 8.03 \\
\hline Paracetamol & 18 & 11.1 \\
\hline Nimesulide & 11 & 6.8 \\
\hline Don't know & 67 & 41.35 \\
\hline No response & 3 & 1.85 \\
\hline \multicolumn{3}{|c|}{ Consumption of which fruit is most beneficial in a patient of dengue? } \\
\hline Papaya & 12 & 7.4 \\
\hline Mango & Nil & Nil \\
\hline Kiwi & 148 & 91.35 \\
\hline Apple & 1 & 0.6 \\
\hline Banana & 1 & 0.6 \\
\hline \multicolumn{3}{|c|}{ What are the complications of dengue fever? } \\
\hline Dengue hemorrhagic fever & 23 & 14.2 \\
\hline Shock & 4 & 2.5 \\
\hline Low platelet count & 89 & 54.9 \\
\hline Dehydration & 9 & 5.6 \\
\hline Death & 15 & 9.3 \\
\hline Don't know & 18 & 11.1 \\
\hline
\end{tabular}

Table 2: Attitude towards dengue.

\begin{tabular}{|lll|}
\hline Questions & Number & Percentage (\%) \\
\hline Do you feel that you are at risk of getting dengue? & & 27.8 \\
Absolutely & 45 & 35.2 \\
Maybe & 57 & 27.2 \\
No, I take all the precautions & 44 & 9.8 \\
Don't know & 16 & \\
\hline Do you think dengue fever is treatable? & 157 & 96.9 \\
Yes & Nil & Nil \\
No & 3 & 1.8 \\
Don't know & 2 & 1.2 \\
No response & & \\
\hline Have you ever tried to treat a relative/ family member/ friend & & \\
suffering from dengue yourself with home remedies? & 148 & 91.4 \\
No & 4 & 2.5 \\
Yes & 10 & 6.2 \\
No response & & \\
\hline Does a patient of dengue require hospitalization? & 74 & 45.7 \\
Definitely & 79 & 48.8 \\
Sometimes & 4 & 2.5 \\
No, he can be treated at home & Nil \\
No treatment required & 2 & Nil \\
Don't know & 3 & 1.2 \\
No response & & 1.8 \\
\hline Is it possible to prevent dengue? & 2 & \\
No & 148 & 1.2 \\
Yes & 5 & 91.4 \\
Maybe & 4 & 3.1 \\
Don't know & 3 & 2.5 \\
No response & & 1.8 \\
\hline
\end{tabular}

Table 3: Practices towards prevention of dengue fever. 


\begin{tabular}{|lll|}
\hline Questions & Number & Percentage (\%) \\
\hline How can dengue be prevented? & & \\
Using mosquito sprays and repellants & 70 & 43.2 \\
Use of bed nets, window and door screens & 20 & 12.3 \\
Wearing full sleeve clothes & 26 & 16.04 \\
Prevent standing water in house or around the house (discarded tyres, & 103 & 63.6 \\
plastic containers, ditches etc) & & 10.5 \\
By tightly covering any water container & 17 & 12.3 \\
Regular cleaning of coolers & 20 & 11.7 \\
Preventing garbage collection & 19 & 11.1 \\
Cut any heavy vegetation around the house & 18 \\
Don't know & 1 & 0.6 \\
\hline Are you aware that government sprays insecticides to control & & \\
mosquitoes? & & 74.1 \\
Yes & 120 \\
No & 42 & 25.9 \\
\hline How often do you clean your water filled containers, coolers and & & \\
ditches around the house \& workplace? & & 25.9 \\
Every alternate day & 42 & 35.8 \\
Once a week & 58 & 8.6 \\
Once in two weeks & 14 & 14.2 \\
Once in a month & 23 & 7.4 \\
Once in six months & 12 & 5.6 \\
Never done it & 9 & 2.5 \\
No response & 4 & \\
\hline Where all do you collect water in your house or workplace? & & 26.5 \\
Open containers (jugs, buckets, vases etc.) & 43 & 43.2 \\
Closed bottles & 70 & 13.6 \\
Coolers & 22 & 0.6 \\
Flower pots & 1 & 19.8 \\
Water dispensers & 32 & 3.1 \\
Others (Buckets with lids, drums, earthen pots) & 5 & 2.5 \\
\hline Have you ever attended dengue prevention lectures/ camps? & & 95.7 \\
Yes & 4 & 1.8 \\
No & 155 \\
No response & 3 & 3.7 \\
\hline Are you a part of any community related programmes for & & 95.7 \\
prevention of dengue? & 6 & 0.6 \\
Yes & 155 \\
No & 1 & \\
No response & & \\
& & \\
\hline
\end{tabular}

About $48.8 \%$ workers agreed that a patient of dengue may require hospitalization while $45.7 \%$ felt that a dengue definitely requires hospitalization. Majority of the respondents $(91.4 \%)$ felt that dengue can be prevented. Table 2 shows that attitudes of workers regarding dengue.

\section{Preventive measures against dengue}

As it has been seen from the above results about knowledge regarding dengue, majority of the respondents know that standing water (coolers, utensils, buckets, and flower pots) is a common breeding place for the Aedes mosquitoes. Therefore $63.6 \%$ replied that by preventing collection of the standing water in and around the house is an important way to prevent dengue spread. Another $43.2 \%$ replied that use of mosquito sprays and repellents can be helpful too. Other methods of prevention of dengue like use of bed nets, window screens, wearing full sleeve clothes, regular cleaning of coolers, covering of water containers, avoiding garbage collection was mentioned by few workers (Table 3). About $74.1 \%$ respondents were aware that government spreads insecticides to control mosquitoes which can prevent dengue. When asked about the frequency with which these workers checked or cleaned their coolers, water containers in the house, $35.8 \%$ checked it once a week, $25.9 \%$ every alternate day, $14.2 \%$ once in a month and others once in two weeks $(8.6 \%)$ or once in six months (7.4\%). A few of them (5.6\%) accepted that they had never bothered to clean these. About $43.2 \%$ said that they collected water in closed containers while $26.5 \%$ still collected water in open containers like jars, buckets etc. Majority of the workers had never attended any dengue 
prevention lectures/camps or been a part of any community related dengue prevention programme (95.7\%, 95.7\% respectively). Just one respondent mentioned that he was an active participant in village community programmes for prevention of dengue.

\section{DISCUSSION}

The present study documents that almost all the participants had heard about dengue and mostly were aware that it is caused by the bite of the mosquito. Similar results have been observed in other studies done in India. ${ }^{2,5,6}$ Majority of the study population was literate and had access to newspapers and television which might be the reason for awareness about dengue fever. Therefore media plays an important role in spreading awareness about such diseases which reaches out to a large number of people across the land. For remote areas, camps/ community lectures should be organized more frequently as more awareness is still required regarding various aspects of dengue like biting habits of the mosquito, mode of transmission and signs and symptoms of the disease. This knowledge about mode of transmission is important as it can help in prevention of dengue while early recognition of signs \& symptoms can lead to timely management \& prevention of complications of dengue. It was good to see that workers were aware that testing facility for dengue was available in many city laboratories and therefore if they suspected any family member or friend of having dengue, immediate medical help could be sought. Regarding the breeding places of the vector, majority knew that stagnant water is the culprit but despite this knowledge, only $61.7 \%$ cleaned their coolers or water containers on alternate days or once a week. Rests of the workers still were less cautious in this aspect. This shows that being literate or being knowledgeable is not associated with being more cautious or practicing cleanliness just as was seen in other studies. ${ }^{2,6}$

The correct treatment measures for dengue after its diagnosis is important so that a patient does not land into its serious complications. The knowledge that for fever, only paracetamol should be consumed and aspirin or ibuprofen should never be taken is still lacking among the general population. The role of health care worker is important here who should be educating people about the correct management of dengue by camps or lectures .Electronic and print media again can play a vital role in dissipation of such information. Many participants knew kiwi is a beneficial fruit in dengue but few considered papaya to be useful especially the juice of papaya rind. Such beliefs/ rituals which usually have no medical basis need to be eradicated from the mind of people as they can worsen the condition of the patient. People need to be educated that they should carefully follow the instructions of the registered medical practitioner and not to self-medicate. Many still think that it is always necessary to hospitalize a dengue patient and hence sometimes due to financial constraints they refrain from consulting a doctor. The need is to spread awareness that if timely management is done with the help of a doctor, patient can be managed at home and hospitalization can be avoided. Proper care of the patient, adequate bed rest and compliance of doctor's instructions can generally treat the patient of dengue.

Most of the respondents were aware of one or the other measures for prevention of dengue like prevention of stagnant water, use of mosquito repellents, wearing full sleeve clothes and regular cleaning of coolers. Also they were aware that government sprays insecticides to control mosquitoes. What is still required is more emphasis on regular practice of these preventive measures which is the only way to limit the spread of the disease, so government should frequently hold campaigns which focus on the importance of exercising of the environmental controls for mosquitoes. ${ }^{4}$

\section{CONCLUSION}

Dengue is a preventable and a treatable disease. The present study showed that many of the participants knew about the disease but the knowledge regarding signs and symptoms was still not sufficient. They were aware that dengue can be treated but many still did not know which medicines should be absolutely avoided to prevent any further complications in a patient of dengue. Awareness about preventive measures is present among many but the practice of the same is not seen in all. There is scarcity of such studies done in Punjab according to our knowledge and more of these studies need to be carried out in other areas. This will highlight the magnitude of knowledge among other population groups and collection of such data can help in identifying the existing gap in the awareness of dengue, its spread, signs \& symptoms, treatment and prevention. Community lectures, health campaigns can be organized to dissipate such information. More information can be disseminated through electronic and print media which can reach to a wider population.

\section{ACKNOWLEDGEMENTS}

We thank the factory workers and their management for the support and participation.

Funding: No funding sources

Conflict of interest: None declared

Ethical approval: The study was approved by the Institutional Ethics Committee

\section{REFERENCES}

1. Khan SA, Dutta P, Topno R, Soni M, Mahanta J. Dengue outbreak in a hilly state of Arunachal Pradesh in Northeast India. Sci World J. 2014;2014:584093.

2. Matta S, Bhalla S, Singh D, Rasania SK, Singh S. Knowledge, attitude \& practice (KAP) on dengue 
fever: a hospital based study. Indian J Comm Med. 2006;31(3):185-6.

3. Why dengue threat could be up to 1000 times bigger than you think. Available at http://indianexpress.com/article/explained/whydengue-threat-could-be-up-to-1000-times-biggerthan-you-think. Accessed 09 December 2015.

4. Malhotra G, Yadav A, Dudeja P. Knowledge, awareness and practices regarding dengue among rural and slum communities in North Indian City, India. Int J Med Sci Public Health. 2014;3(3):295-9.

5. Chinnakali P, Gurnani N, Upadhyay RP, Parmar K, Suri TM, Yadav K. High level of awareness but poor practices regarding dengue fever control: a cross sectional study from North India. N Am J Med Sci. 2012;4(6):278-82.

6. Malhotra V, Kaur P. The community knowledge, attitude and practices regarding dengue fever in field practice area of urban training health centre of Patiala. Int J Res Dev Health. 2014;2(1):19-26.

Cite this article as: Tikoo D, Sharma G, Gupta M. Assessment of knowledge, attitude and practice of dengue in factory workers of Amritsar, Punjab. Int $\mathbf{J}$ Basic Clin Pharmacol 2016;5:38-44. 